\title{
Fracture of an esophageal stent: a rare but significant complication
}

Self-expanding metal stents are commonly used to palliate malignant dysphagia. Typical complications include hemorrhage, ulceration, perforation or fistula, compression of the trachea, stent migration, and tumor ingrowth [1,2]. We report fracture of an esophageal stent as an unusual complication.

A 50-year-old man was found on endoscopy to have a lower esophageal tumor. Biopsy confirmed a poorly differentiated adenocarcinoma. Palliative chemotherapy was initiated and an $18 \mathrm{~mm} \times 11 \mathrm{~cm}$ esophageal Choo stent (M.I. Tech, Seoul, South Korea) was placed to prevent dysphagia. This stent type has a segmented body, the individual mesh segments being linked by a polymer covering.

Seven months later, the patient re-presented with coffee-ground vomiting and dysphagia. Endoscopy demonstrated fracture of the stent. A proximal segment had separated from the main stent body and was freely mobile in the esophagus, causing local trauma and bleeding that required transfusion. The main body was still covering the distal two-thirds of the tumor. The mobile fragment was extracted endoscopically. A $12 \mathrm{~cm}$ Ultraflex stent (Boston Scientific, Natick, Massachusetts, USA) was placed across the exposed up- per end of the tumor and the remaining parts of the Choo stent. This relieved the patient's symptoms until his death.

Fracture of an esophageal stent is a rarely encountered complication. A Medline search revealed only three reports on four patients. The authors of these reports believe that the fractures were caused by thermal overstrain induced by laser application [3] or defective material at the time of deployment [4], or that they were spontaneous $[4,5]$. Our patient suffered a spontaneous stent fracture, his stent breaking in the polymer connection between metal mesh segments. It seems likely that the design of the Choo stent (individual segments of mesh connected by the polymer covering of the stent) may have contributed to this unusual event. We advise including failure of device and/or stent fracture as potential complications in the information given to patients before they consent to stent insertion.

Endoscopy_UCTN_Code_CPL_1AH_2AD

\section{S. K. Chhetri, C. P. Selinger, S. Greer}

Department of Gastroenterology, Royal Albert Edward Infirmary, Wigan, UK
References

1 Winkelbauer FW, Schofl R, Niederle B et al. Palliative treatment of obstructing esophageal cancer with nitinol stents: value, safety, and long-term results. AJR Am J Roentgenol 1996; 166: 79-84

2 Acunas B, Rozanes I, Akpinar $S$ et al. Palliation of malignant esophageal strictures with self-expanding nitinol stents: drawbacks and complications. Radiology 1996; 199: $648-652$

3 Schoefl R, Winkelbauer F, Haefner $M$ et al. Two cases of fractured esophageal nitinol stents. Endoscopy 1996; 28: $518-520$

4 Grimley CE, Bowling TE. Oesophageal metallic stent dysfunction: first reported case of stent fracture and separation. Endoscopy 1999; 31: S45

5 Reddy AV, Alwair H, Trewby PN. Fractured esophageal nitinol stent: report of two fractures in the same patient. Gastrointest Endosc 2003; 57: 138 - 139

Bibliography

DOI 10.1055/s-2008-1077463

Endoscopy 2008; 40: E199

(c) Georg Thieme Verlag KG Stuttgart · New York . ISSN 0013-726X

Corresponding author

C. Selinger, MD

Royal Albert Edward Infirmary

Wigan Lane

Wigan

WN1 2NN

UK

Fax: +44-1942-778634

Christian.selinger@web.de 